Original Research Paper

\title{
Sensitive and Rapid Detection of Sulfate-Reducing Bacteria in Jet Fuel by Loop-Mediated Isothermal Amplification Combined with Lateral Flow Dipstick
}

\author{
${ }^{1}$ Zezhen Li, ${ }^{1}$ Yun Xiong, ${ }^{2}$ Peng Zhu and ${ }^{3}$ Hailong Huang \\ ${ }^{I}$ Deptartment of Oil Application and Management Engineering, \\ Logistical Engineering University, Chongqing, China \\ ${ }^{2}$ Sinopec Zhenhai Refining \& Chemical Corps Room, Ningbo, China \\ ${ }^{3}$ Key Laboratory of Applied Marine Biotechnology, Ningbo University, Ningbo, China
}

Article history

Received: $25-02-2018$

Revised: 02-04-2018

Accepted: 10-04-2018

Corresponding Author:

Yun Xiong

Deptarment of Oil Application and Management Engineering, Logistical Engineering University, Chongqing, China Email: lzzlovefree@qq.com

\begin{abstract}
The existence of Sulfate-Reducing Bacteria (SRB) is one of the significant reasons for the Microbially Influenced Corrosion (MIC) of jet fuel. Especially for the jet fuel stored by military, since jet fuel is stored in the tank for a long time, some oxygen-consuming bacteria such as Amorphotheca resinae and Bacillus Cohn can consume oxygen and generate organic acids at the oilwater interface of the tank bottom. This causes anaerobic SRB flourish in fuel tanks. In this study, a loop-mediated isothermal amplification (LAMP) combined with a chromatographic Lateral Flow Dipstick (LFD) assay was established to detect the SRB. Four groups of LAMP primers were designed and synthesized to target dsrB (dissimilatory sulfite reductase $\beta$-subunit) genes in SRB.LAMP-LFD can detect $121 \mathrm{fg} / \mu \mathrm{L}$ of SRB DNA within $35 \mathrm{~min}$. The detection limit of this method is 1000 times more sensitive than the conventional PCR and shortens the detection time greatly. This method is negative for other eight common bacteria species in jet fuel, indicating that the method has high specificity. In summary, this method can be used to detect the presence of SRB in jet fuel.
\end{abstract}

Keywords: Protein-Protein Interaction Networks, Essential Proteins, Network Centrality, Network Topology, Subcellular Localization Information, Protein Complexes

\section{Introduction}

When conditions are quiescent and anaerobic, SRB can utilize organic matter on the metal surface as a carbon source and hydrogen generated within biofilm to reduce the sulfate to hydrogen sulfide and obtain viable energy from redox reactions (Hill, 2003). The resulting sulfide can dissolve in fuel and this fuel becomes aggressive to steel, silver and yellow metals. SRB (mainly Desulfovibrio $s p$. and the more oxygen tolerant Desulfotomaculum sp.) has been isolated in some heavily contaminated tanks (Rauch et al., 2006). The toxic substances produced by SRB can inhibit the growth of other fungi and react with iron to form ferrous sulfide that causes the water at the bottom of the tank to become black (Hill and Hill, 2000). The Institute of Petroleum indicates that microbial counts in the water bottom are $10^{9}-10^{11} \mathrm{CFU} / \mathrm{L}$ bacteria, $10^{7}-10^{10} \mathrm{CFU} / \mathrm{L}$ yeasts, $10^{6}$ $\mathrm{CFU} / \mathrm{L}$ molds and $10^{5} \mathrm{CFU} / \mathrm{L} \mathrm{SRB}$, either alone or in combination are considered to represent microbial contamination (Institute of Petroleum, 1996). At present, the detection of SRB mainly relies on the traditional culture method, for example Most Probable Number (MPN) (Mccrady, 1915), which provides high precision but takes more than 15 days. Therefore, a rapid detection method for SRB is required. Dissimilatory Sulfite Reductase (DSR) is a key enzyme in SRB dissimilatory sulfate reduction (Islamud-Din et al., 2014). DSR catalyzes the six electron reduction of sulfite to sulfide. The reaction is the last step in the respiration of sulphate, which is only in alien sulfate-reduced prokaryotes presently. The ubiquity of DSRs and their highly conserved sequences make this enzyme be suited for the detection of SRB (Ryuji et al., 2004).

In this study, we selected dsrB gene as a targeted gene. First, two primers (DSRp2060F and DSR4R) (Geets et al., 2006) were used for PCR amplification and the products were purified and sequenced. LAMP 
primers were designed according to the sequencing results. Loop-mediated isothermal amplification (LAMP) is a novel method developed by Notomi et al. (2000). Compared with the PCR technology, LMAP has the advantages of high specificity, high sensitivity, simple operation, independent of professional equipment and short time-consuming (Tomita et al., 2008). In recent years, LAMP was widely used (Mori et al., 2004). The invention is characterized that four specific primers are designed according to six characteristic fragments of the target gene: a forward-outer primers B3 and a backwardinner primer B3, a Forward-Inner Primer (FIP) and a Backward-Inner Primer (BIP) (Notomi et al., 2015). The circular DNA can be displaced with Bst DNA polymerase under isothermal condition. Then some researchers tried to combine LAMP with nucleic acid lateral flow test strip detection (LAMP-LFD) (Kiatpathomchai et al., 2008) and LAMP-LFD enables rapid visualization of test results. The principle is (Prompamorn et al., 2011; Ding et al., 2010; Chowdry et al., 2014): The biotin-labeled nucleic acid product is hybridized to a specific probe labeled with Fluorescein Isothiocyanate (FITC). Then a small amount of LAMP amplification product was added to the LFD strip, or put test strip vertically into the LAMP amplification product with detection buffer. The chromatographic membrane diffusion of immune complexes through the strip, the biotin-labeled nucleic acid amplification product is captured by the biotin ligand on the test strip to form a visually detectable colored test line when the immune complexes diffuse to the test strip. Immune complexes that are not captured by the biotin ligand continue to diffuse under the action of the chromatographic membrane; eventually immune complexes are captured by the specific antibodies to form a visually control line. Throughout the experimental operation, the operator does not rely on any special equipment, only needs to put the LAMP amplification products and test strips into the buffer to achieve the specific detection of the target product. The entire operation is simple, safe with visible results. LAMP-LFD technology has been applied by many researchers and widely used in the detection of fungi, bacteria and viruses (Jaroenram et al., 2009; Nimitphak et al., 2010; Plaon et al., 2011). This method has great promotion prospect in the rapid biological detection.

\section{Materials and Methods}

Samples cultivation and collection. The two SRB species used in this experiment were obtained from China General Microbiological Culture Collection Center (CGMCC) and the other eight bacteria species were obtained from the China Center of Industrial Culture Collection (CICC). The following bacteria species were cultured for experiments control: Desulfotomaculum ruminis, Desulfovibrio fructosivorans, Bacillus subtilis,
Pseudomonas aeruginosa, Pantoea sp, Massilia neuensis, Paenibacillus sp, Methylobacterium sp, Escherichia coli, Staphylococcus aureus (Table 1). Two sulfate-reducing bacteria were placed in an anaerobic workstation at $37^{\circ} \mathrm{C}$, postgate's $\mathrm{C}$ medium. Other bacteria species were grown to plateau phase under the same culture conditions before the experiments.

DNA extraction. Genomic DNA of the ten bacteria species was extracted using a TaKaRa MiniBEST Bacteria Genomic DNA Extraction Kit Ver. (Takara Biotechnology Co., Ltd., Beijing, China) according to the instructions of manufacturer. Briefly, $1.5 \mathrm{~mL}$ of the bacteria cells were lysed by a lysis buffer with RNaseA $(10 \mathrm{mg} / \mathrm{mL})$ and Proteinase $\mathrm{K}(20 \mathrm{mg} / \mathrm{mL})$ for $10 \mathrm{~min}$ at $56^{\circ} \mathrm{C}$. The genomic DNA was eluted with $50 \mu \mathrm{L}$ of elution buffer. Finally, DNA quality was verified by spectrophotometer (Thermo Scientific NanoDrop $2000 \mathrm{C}$, USA) and stored at $-80^{\circ} \mathrm{C}$ till $\mathrm{PCR}$ and LAMP-LFD were performed.

PCR amplification and analysis of dsrB gene fragments. Ten samples of DNA were subjected to PCR amplification using DSRp2060F and DSR4R primers. The PCR experiments were performed in an Eppendorf Mastercycler gradient PCR (Eppendorf China Ltd.) in a $50-\mu \mathrm{L}$ volume with the specific primers. The PCR mixture contained $20 \mu \mathrm{M}$ DSRp2060F and DSR4R, $5 \mathrm{U}$ Ex Taq DNA polymerase, $2.5 \mu \mathrm{L} 10 \times$ buffer, $2.5 \mathrm{mM}$ dNTPs and $2 \mu \mathrm{L}$ DNA template. The reaction conditions were as follows: $94^{\circ} \mathrm{C}$ for $8 \mathrm{~min} ; 35$ cycles of $40 \mathrm{~s}$ at $94^{\circ} \mathrm{C} 40 \mathrm{~s}$ at $55^{\circ} \mathrm{C}$ and $90 \mathrm{~s}$ at $72^{\circ} \mathrm{C}$; and a final extension at $72^{\circ} \mathrm{C}$ for $10 \mathrm{~min}$. Samples $(5 \mu \mathrm{L})$ of the PCR amplification products were examined on $1.5 \%$ of agarose ethidium bromide-stained gels. The $350 \mathrm{bp}$ fragments were expected from the dsrB gene targets of SRB and the PCR amplification products of SRB were sent to Novogene Bioinformatics Technology Co., Ltd., Beijing for sequencing-by-synthesis. Ultrapure water was used as the negative control.

LAMP primers and probes design. Comparing the sequencing results of two SRB species of PCR amplification products, LAMP primers and LFD probe were designed by Primer Explorer V5 (http://primerexplorer.jp/) according to the conserved region of dsrB gene. The primer design sequences are given in Table 2. The primers were synthesized by Takara Biotechnology Co., Ltd., Dalian, China.

The LAMP and LAMP-LFD reactions. The LAMP reaction was carried out at 61,63 and $65^{\circ} \mathrm{C}$ for $50 \mathrm{~min}$ and then the optimal reaction conditions and the primers in Table 2 were screened out by the quantitative PCR thermal cycler. The reactions contain the following reagents: A 20 $\mu \mathrm{L}$ total reaction mixture containing $2 \times$ reaction $(\mathrm{BQE} 2)$ buffer (Beijing Boao Biotechnology Co. Ltd., Beijing, China), 5 pmol F3 and B3, 20 pmol FITC-labeled LF and LB, 40 pmol biotin-labeled FIP and BIP, $2 \mu \mathrm{L}$ of 
Desulfotomaculum ruminis DNA and $5 \mu \mathrm{L}$ of ultrapure water. After the biotin-labeled LAMP reaction finished, 8 $\mu \mathrm{L}$ of the hybridization solution was added to $100 \mu \mathrm{L}$ detection buffer in a new tube. Finally, the LFD strip was dipped into the mixture and the detection result appeared after $5 \mathrm{~min}$. The assay results were determined through observing the control and test lines on the LFD strips. Ultrapure water was used as the negative control.

Specificity detection by PCR, LAMP and LAMP-LFD assays. DNA templates of 2 SRB species and 8 other common bacteria in jet fuels in Table 1 were extracted. PCR amplification was performed using DSRp2060F and DSR4R primers and PCR reaction results were analyzed with $1.5 \%$ AGE followed by ethidium bromide staining and visualization by the UV transilluminator. LAMP reaction was performed under the optimal conditions; results were analyzed by the quantitative PCR thermal cycler and LFD as described above.

Sensitivity detection by PCR, LAMP and LAMP-LFD assays. Initial concentration of Desulfotomaculum ruminis DNA template is $121 \mathrm{ng} / \mu \mathrm{L}$. Taking $1 \mu \mathrm{L}$ of the original DNA template added to $9 \mu \mathrm{L}$ ultrapure water for 10-fold gradient. Diluted DNA templates were performed separately by PCR, LAMP and LAMP-LFD reactions. PCR amplification was performed using DSRp2060F and DSR4R primers. LAMP reaction was performed under the optimal conditions; results were analyzed by the quantitative PCR thermal cycler and LFD as described above.

Stability detection by LAMP and LAMP-LFD assays. According to the test results in 2.7, take the corresponding dilution of the DNA template for LAMP and LAMP-LFD reaction as described above. And the experiment was repeated 3 times. Ultrapure water was used as the negative control.

\section{Results}

Optimal LAMP primers and reaction conditions. The LAMP reaction was carried out at 61,63 and $65^{\circ} \mathrm{C}$ for $50 \mathrm{~min}$ and then the optimal reaction conditions and the primers in Table 2 were screened out by the quantitative PCR thermal cycler. As the result shows in Fig. 1, $\mathrm{SRB} 73$ at $65^{\circ} \mathrm{C}$ and $\mathrm{SRB} 72$ at $63^{\circ} \mathrm{C}$ started the reaction at $10 \mathrm{~min}$, reached equilibrium at $25 \mathrm{~min}$ and the reaction time was the shortest. However, SRB73 primer had higher fluorescence intensity and SRB73 was selected as the best primer. The optimal reaction conditions were $65^{\circ} \mathrm{C}$ for $25 \mathrm{~min}$.

Specificity detection: Use the two SRB species and Bacillus subtilis, Paenibacillus sp, Methylobacterium sp., Pantoea sp, Staphylococcus aureus, Escherichia coli, Massilia neuensis and Pseudomonas aeruginosa species in Table 1 for specific detection. The results shown in Fig. 2.

Table 1: Bacteria species for LAMP-LFD assay

\begin{tabular}{ll}
\hline Bacteria species & Source \\
\hline Desulfotomaculum ruminis & CGMCC 1.3468 \\
Desulfovibrio fructosivorans & CGMCC 1.3470 \\
Bacillus subtilis & CICC 10028 \\
Paenibacillus sp. & CICC 10541 \\
Methylobacterium sp. & CICC 10507 \\
Pantoea sp. & CICC 10575 \\
Staphylococcus aureus & CICC 10001 \\
Escherichia coli & CICC 23796 \\
Massilia neuensis & CICC 24113 \\
Pseudomonas aeruginosa & CICC 10205 \\
\hline
\end{tabular}

Table 2: Four group primers of sulfate-reducing bacteria for LAMP assay

\begin{tabular}{|c|c|c|c|}
\hline Primer & Type & Length & Sequence( $\left.5^{\prime}-3{ }^{\prime}\right)$ \\
\hline SRB -1-F3 & Forward-outer primer & 17 & GTGACGCGACGGAGTTG \\
\hline SRB -1-B3 & Backward-outer primer & 18 & TGCTGCCTGAACATGTGC \\
\hline SRB -1-FIP & Forward-inner primer(F1c+F2) & 38 & ATCCCGCTGGCCATCTCCG-ACCTTCTTGCCGTCGATCT \\
\hline SRB -1-BIP & Backward-inner primer(B1c+B2) & 39 & TTCGCAGATGTTGTCCAGGCG-GCTCCGACATCGGCATCG \\
\hline SRB -1-LB & Loop-backward primer & 19 & GTTCGACGATCGGCGGCTT \\
\hline SRB -72-F3 & Forward-outer primer & 19 & GACCTTGGTCGGCTTGATG \\
\hline SRB -72-B3 & Backward-outer primer & 18 & GGCCGTCATGGACGAAAT \\
\hline SRB -72-FIP & Forward-inner primer(F1c+F2) & 36 & CCGCCGATCGTCGAACACG-GAGATGGCCAGCGGGAT \\
\hline SRB -72-BIP & Backward-inner primer(B1c+B2) & 34 & ACGGCGCCGCACATGT-TCCAGTCCATGACCCTGC \\
\hline SRB -72-LF & Loop-forward primer & 19 & GCCTGGACAACATCTGCGA \\
\hline SRB -73-F3 & Forward-outer primer & 18 & CCTTGGTCGGCTTGATGG \\
\hline SRB -73-B3 & Backward-outer primer & 18 & CCAGTCCATGACCCTGCC \\
\hline SRB -73-FIP & Forward-inner primer(F1c+F2) & 37 & CCGCCGATCGTCGAACACG-GAGATGGCCAGCGGGATT \\
\hline SRB -73-BIP & Backward-inner primer(B1c+B2) & 35 & CTTGCGGTGGATGCCGACG-TGGCCTGCTGCCTGAA \\
\hline SRB -73-LF & Loop-forward primer & 19 & GCCTGGACAACATCTGCGA \\
\hline SRB -73-LB & Loop-backward primer & 19 & TGCCGATGTCGGAGCAGTG \\
\hline SRB -76-F3 & Forward-outer primer & 16 & AGATGGCCAGCGGGAT \\
\hline SRB -76-B3 & Backward-outer primer & 18 & GGCCGTCATGGACGAAAT \\
\hline SRB -76-FIP & Forward-inner primer(F1c+F2) & 39 & GCATCGTCGGCATCCACCG-TTCGCAGATGTTGTCCAGGC \\
\hline SRB -76-BIP & Backward-inner primer(B1c+B2) & 36 & ACGGCGCCGCACATGT-ACTTCCAGTCCATGACCCTG \\
\hline SRB -76-LF & Loop-forward primer & 19 & CCGATCGTCGAACACGACC \\
\hline
\end{tabular}




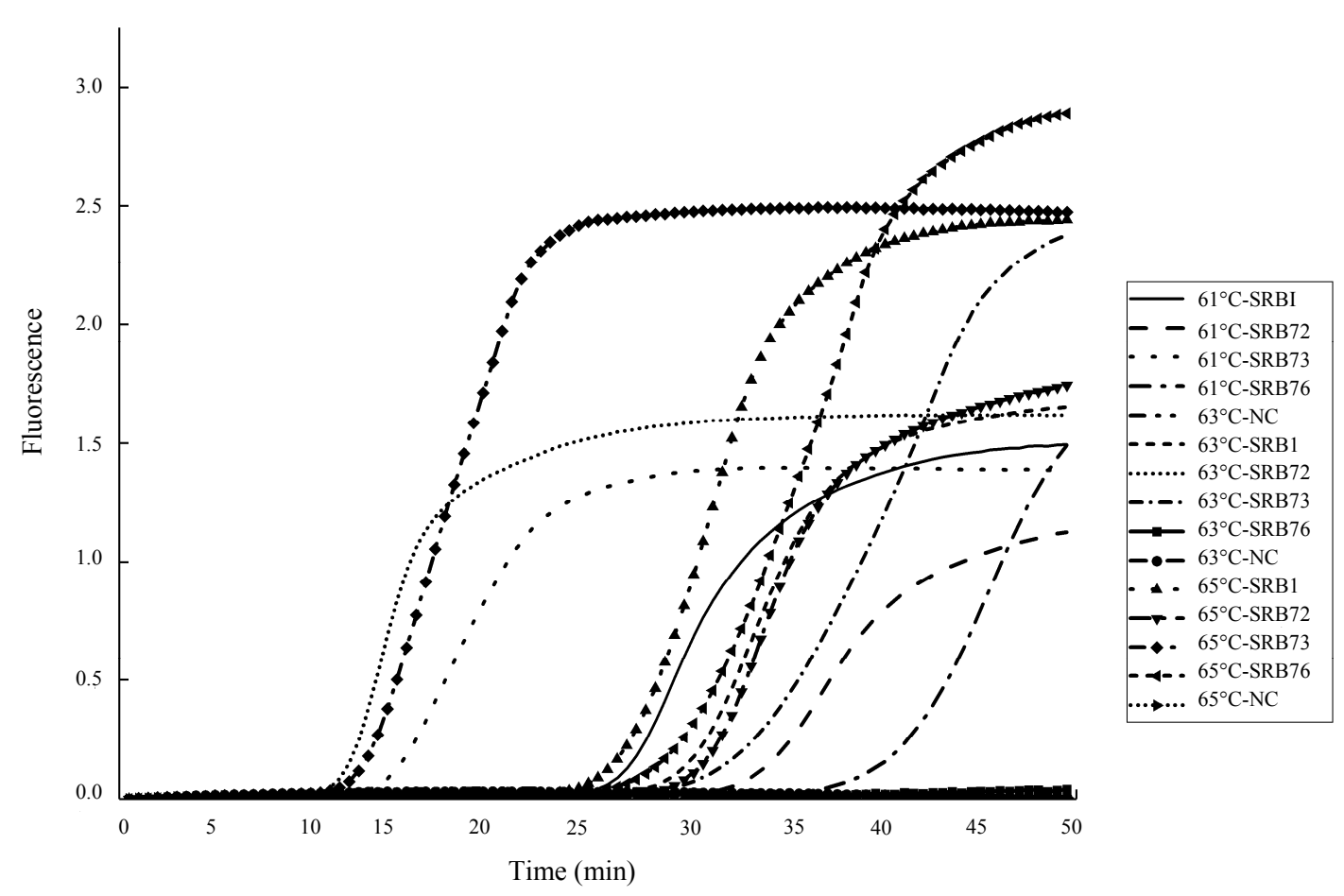

Fig. 1: Optimization of the LAMP reaction conditions and primers for SRB detection. Four sets of primers (SRB-1, SRB-72, SRB-73 and SRB-76respectively) amplified in real-time PCR device at 61,63 and $65^{\circ} \mathrm{C}$ respectively. NC: ultrapure water as DNA template

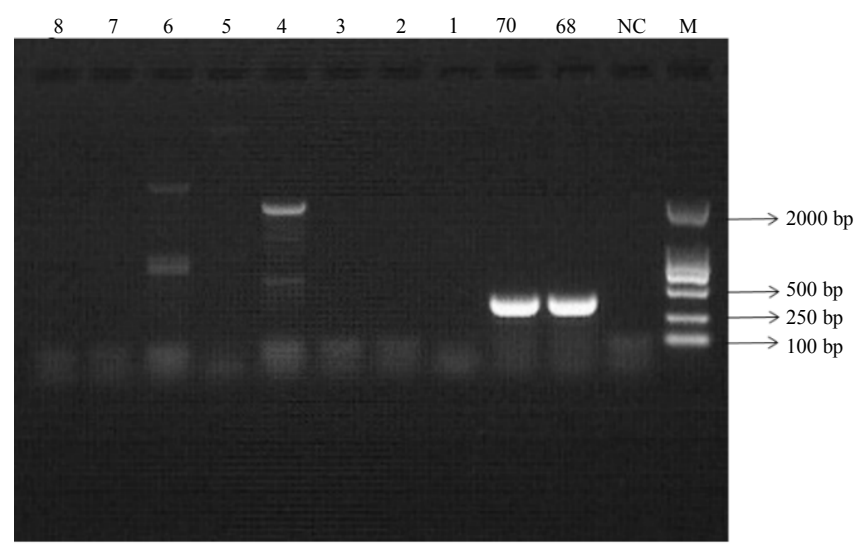

(A)

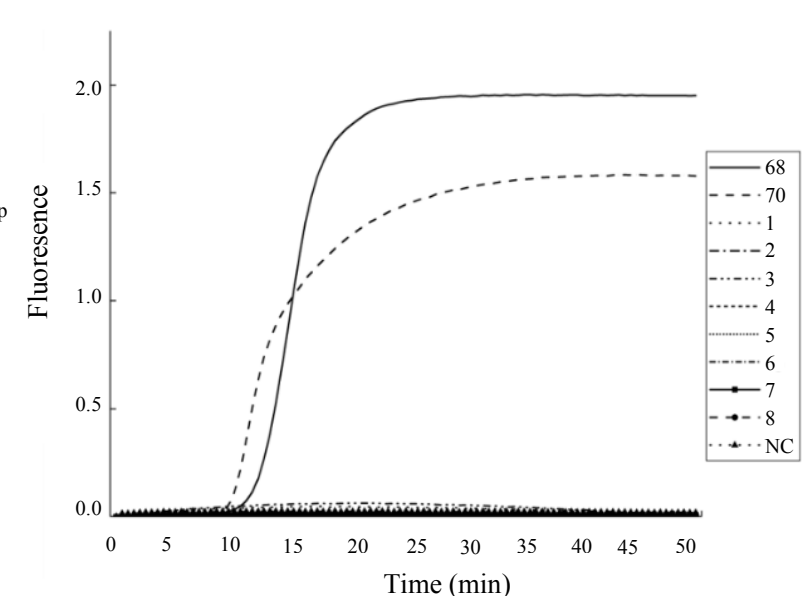

(B)

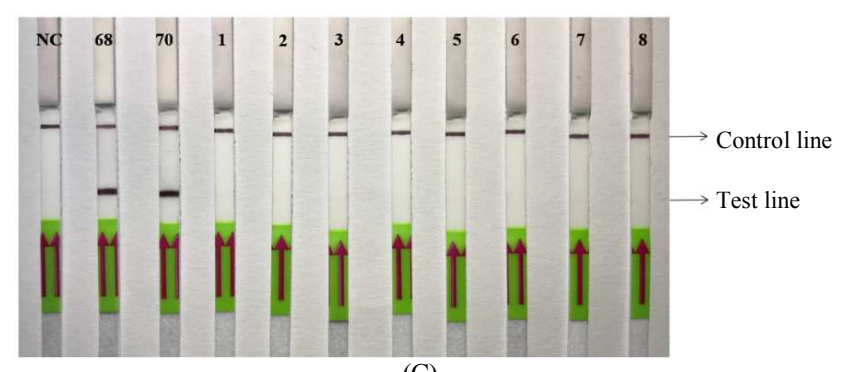

(C)

Fig. 2: Specificity of SRB detection by PCR (A), LAMP (B), and LAMP-LFD (C). M: DL 2000-bp DNA marker. Lanes 68, 70 and 1-8: With Desulfotomaculum ruminis, Desulfovibrio fructosivorans, Bacillus subtilis, Paenibacillus sp, Methylobacterium sp, Pantoea sp, Staphylococcus aureus, Escherichia coli, Massilia neuensis, Pseudomonas aeruginosa. NC: Ultrapure water as DNA template 
Primers DSRp2060F and DSR4R were used in PCR amplification. Figure 2A showed that about $350 \mathrm{bp}$ of the target product was amplified by PCR amplification of two SRB species and strains Pantoea $s p$ and Escherichia coli were also positive. SRB73 primers were used to react for $50 \mathrm{~min}$ at $65^{\circ} \mathrm{C}$ in LAMP and LAMP-LFD amplification. Figure $2 \mathrm{~B}$ and $\mathrm{C}$ showed that only two SRB species were positive with no nonspecific amplification. Thereby, the LAMP-LFD method is more specific than conventional PCR.

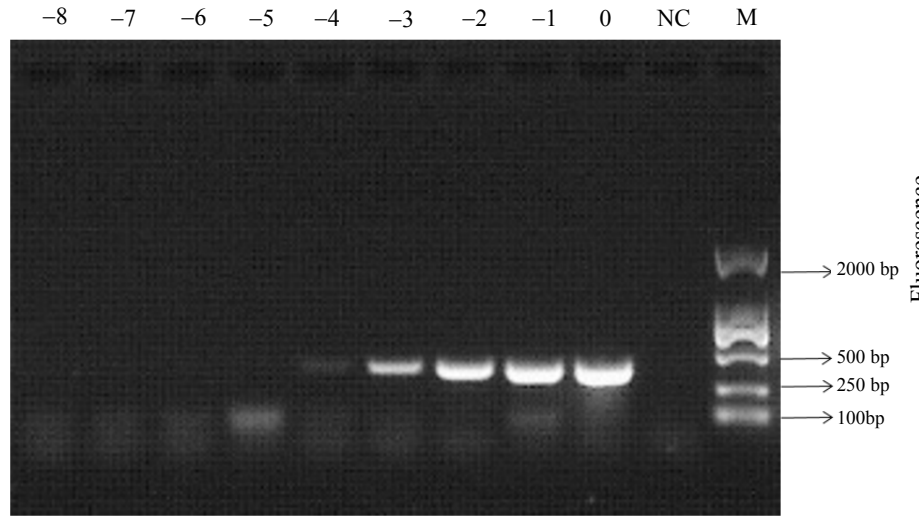

(A)

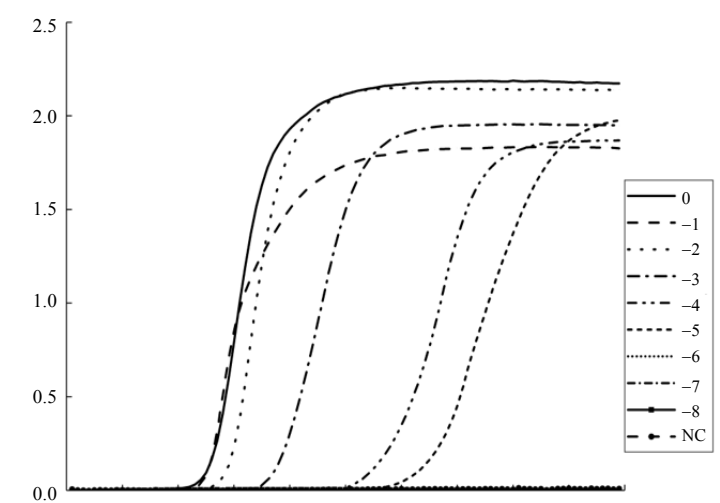

(B)

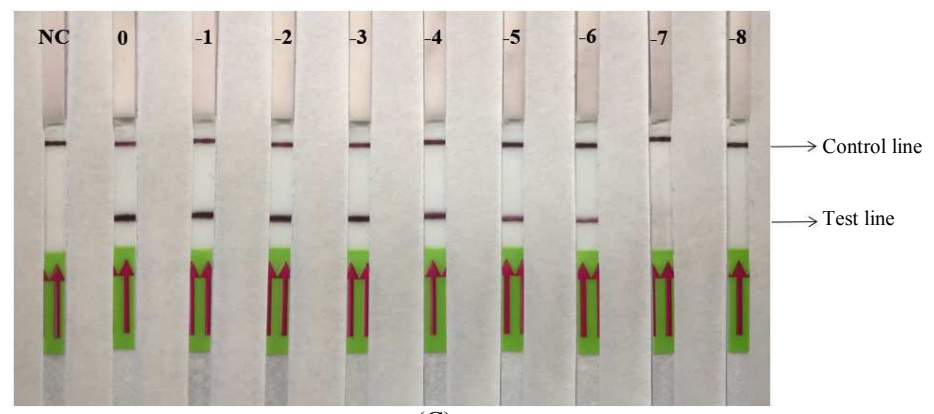

(C)

Fig. 3: The sensitivity of the PCR (A), LAMP (B), and LAMP-LFD (C) for Desulfotomaculum ruminis. M: DL 2000-bp DNA marker. 10fold serial dilutions of Desulfotomaculum ruminis (0-8) at $121,12.1$, and1.21ng/ $\mu \mathrm{L}$ and $121,12.1,1.21 \mathrm{pg} / \mu \mathrm{L}$ and $121,12.1,1.21$ $\mathrm{fg} / \mu \mathrm{L}$ were used as templates for PCR (A), LAMP (B), and LAMP-LFD (C) analysis. NC: Ultrapure water as DNA template
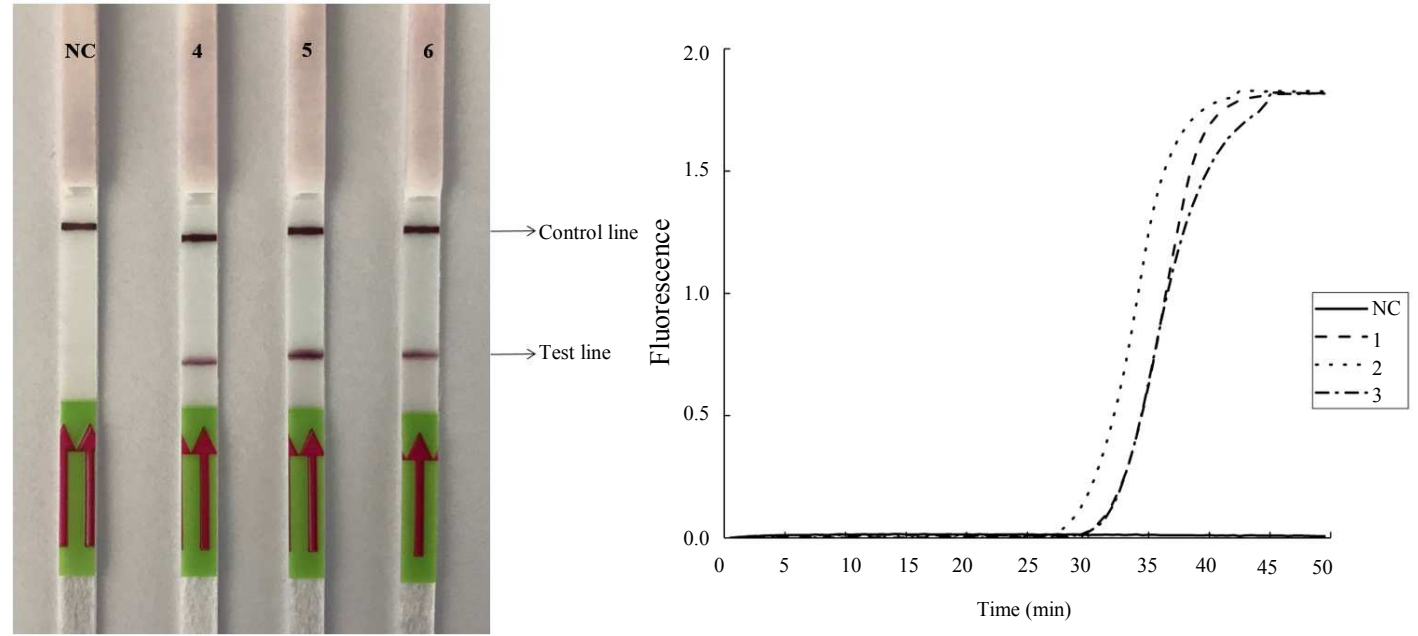

Fig. 4: Repeatability of LAMP and LAMP-LFD assay for Desulfotomaculum ruminis detection. Lanes 1-3: used Desulfotomaculum ruminis genomic DNA $(1.21 \mathrm{pg} / \mu \mathrm{L})$ as a template. Lanes 4-6: Used Desulfotomaculum ruminis genomic DNA $(121 \mathrm{fg} / \mu \mathrm{L})$ as a template. NC: ultrapure water as DNA template 
Sensitivity detection: The detection limits of PCR, LAMP and LAMP-LFD were examined by gradient dilution of template DNA. Primers DSRp2060F and DSR4R were used in PCR amplification. SRB73 primers were used to react for $50 \mathrm{~min}$ at $65^{\circ} \mathrm{C}$ in LAMP and LAMP-LFD amplification. The Fig. 3A showed the limit of conventional PCR detection is $12.1 \mathrm{pg} / \mu \mathrm{L}$; Fig. 3B showed the limit of LAMP detection is $1.21 \mathrm{pg} / \mu \mathrm{L}$ and Fig. 3C showed the limit of LAMP-LFD detection is $121 \mathrm{fg} / \mu \mathrm{L}$. In general, limit of LAMP-LFD detection was 10 -fold more sensitive than the LAMP and 100-fold more sensitive than conventional PCR. LAMP-LFD is more convenient and precise.

Repeatability detection: LAMP and LAMP-LFD reactions were performed with DNA templates at the concentrations of $1.21 \mathrm{pg} / \mu \mathrm{L}$ and $121 \mathrm{fg} / \mu \mathrm{L}$ respectively. SRB73 primers were used to react for 50 min at $65^{\circ} \mathrm{C}$ in LAMP and LAMP-LFD amplification. The experiment was repeated 3 times to investigate the stability of the assay. Fig. 4 showed the experiment results are the same, demonstrating that the LAMP-LFD method can detect SRB steadily.

\section{Discussion}

Although many SRB detection methods have been reported so far, the detection method widely used is still the traditional MPN method. This method is highly specific and sensitive; however the MPN method often takes a long cultivation time and requires at least 15 days completing the entire assay. Due to the long detection time, the results cannot fully reflect the number of SRB in the environment. Other SRB detection methods also have their own deficiencies. For example, assays based on biological compounds such as adenosyl sulfate reductase are less sensitive and require destruction of the SRB cell structure. Analytical methods based on molecular biology such as polymerase chain reaction require high cost and professional skill. Therefore, these SRB detection methods are lack of universality and practicality and they are less used in practical applications.

The LAMP-LFD method is easy to operate and does not require expensive instruments during the detection. The whole experiment process has no complicated operation and it does not need to visualize the test results by AGE analyzation and UV transilluminator compared with the PCR method. LAMP-LFD only needs one detection strip to complete the visualization of the detection result and largely promotes field application of LAMP-LFD method.

It is very important to select the appropriate targetgene for the molecular detection of microbial diversity. Target genes generally include 16S rRNA genes and functional genes. The 16S rRNA gene carries a large amount of sequence information that can be used to design primers and is one of the most widely used target genes. Another important targeted $\mathrm{r}$ gene is a functional gene that can mark microorganisms with specific physiological and metabolic functions. Therefore, DsrB is as a target gene in this study.

In this study, four groups of LAMP primers were designed for SRB and the optimal reaction temperature and primers were obtained by primer screening under different temperature conditions. The amplification reaction can be completed in $30 \mathrm{~min}$. Afterwards, the DNA of common bacteria in jet fuel was extracted and verified specifically. The results showed that the specificity of LAMP and LAMP-LFD was better than the conventional PCR. The detection sensitivity and stability of the LAMP-LFD method were examined and the DNA of the SRB with the lowest concentration of $121 \mathrm{fg} / \mu \mathrm{L}$ can be stably detected. Generally, the LAMP-LFD method established in this study can be used for rapid detection of SRB in jet fuel.

\section{Conclusion}

Aiming at the various potential threats of SRB in jet fuel, a rapid detection LAMP-LFD method was established in this study. Four groups of LAMP primers were designed and synthesized to target dsrB genes in SRB. The LAMP-LFD can detect $121 \mathrm{fg} / \mu \mathrm{L}$ of SRB DNA within $35 \mathrm{~min}$. The detection limit of this method is 1000 times more sensitive than the conventional PCR and greatly shortens the detection time greatly. The method can obtain the result within $30 \mathrm{~min}$; the sensitivity is high and the specificity is qualified; the special instrument is not demanded and the operation is simple. The method is suitable for the on-line monitoring of SRB in jet fuel.

\section{Acknowledgement}

We are grateful to thank the sinopec zhenhai refining and chemical corps room for their cooperation and technical guidance during the study period. We are also grateful thankful to Sr. Chen for his help during the writing period.

\section{Author's Contributions}

Zezhen Li: He designed the research plan and organized the study.

Yun Xiong: He participated in all experiments, coordinated the data-analysis and contributed to the writing of the manuscript.

Peng Zhu: He participated to collect the materials related to the experiment.

Hailong Huang: It is contributed to get support from the supporters. 


\section{Conflict of Interest}

The authors declare that they have no competing interests. The corresponding author affirms that all of the authors have read and approved the manuscript.

\section{Ethics}

This article is original and contains unpublished material. The corresponding author confirms that all of the other authors have read and approved the manuscript and there are no ethical issues involved.

\section{References}

Chowdry, V. K., Y. Luo, F. Widén, H.J. Qiu and H. Shan et al., 2014. Development of a loopmediated isothermal amplification assay combined with a lateral flow dipstick for rapid and simple detection of classical swine fever virus in the field. J. Virol. Methods, 197: 14-18.

DOI: 10.1016/j.jviromet.2013.11.013

Ding, W.C., J. Chen, Y.H. Shi, X.J. Lu and M.Y. Li, 2010. Rapid and sensitive detection of infectious spleen and kidney necrosis virus by loop-mediated isothermal amplification combined with a lateral flow dipstick. Archives Virol., 155: 385-389.

DOI: $10.1007 / \mathrm{s} 00705-010-0593-4$

Geets, J., B . Borremans, L. Diels, D. Springael and J. Vangronsveld et al., 2006. Dsrb, gene-based dgge for community and diversity surveys of sulfatereducing bacteria. J. Microbiol. Methods, 66: 194-205. DOI: $10.1016 /$ j.mimet.2005.11.002

Hill, E.C. and G.C. Hill, 2000. Detection and remediation of microbial spoilage and corrosion in aviation kerosene - from refinery to wing. Proceedings of the 7th International Conference on Stability and Handling of Liquid Fuels, (HLF' 00), pp: 1-25.

Hill, T., 2003. Microbial growth in aviation fuel. Aircraft Eng. Aerospace Technol., 75: 497-502.

DOI: $10.1108 / 00022660310492582$

Institute of Petroleum, 1996. Guidelines for the Investigation of the Microbial Content of Fuel Boiling Below $390^{\circ} \mathrm{C}$ and Associated Water. 1st Edn., Institute of Petroleum, London.

Islamud-Din, E.L. Hesham, A. Ahmad, C. Daqiang and S. Khan, 2014. Pcr-dgge and real-time per dsrb -based study of the impact of heavy metals on the diversity and abundance of sulfate-reducing bacteria. Biotechnol. Bioprocess Eng., 19: 703-710. DOI: $10.1007 / \mathrm{s} 12257-014-0324-\mathrm{x}$

Jaroenram, W., W. Kiatpathomchai and T.W. Flegel, 2009. Rapid and sensitive detection of white spot syndrome virus by loop-mediated isothermal amplification combined with a lateral flow dipstick. Molecular Cell. Probes, 23: 65-70.

DOI: $10.1016 /$ j.mcp.2008.12.003
Kiatpathomchai, W., W. Jaroenram, N. Arunrut, S. Jitrapakdee and T.W. Flegel, 2008. Shrimp taura syndrome virus detection by reverse transcription loop-mediated isothermal amplification combined with a lateral flow dipstick. J. Virol. Methods, 153: 214-217. DOI: 10.1016/j.jviromet.2008.06.025

Mccrady, M.H., 1915. The numerical interpretation of fermentation-tube results. J. Infect. Dis., 17: 183-212. DOI: 10.1093/infdis/17.1.183

Mori, Y., M. Kitao, N. Tomita and T. Notomi, 2004. Real-time turbidimetry of lamp reaction for quantifying template DNA. J. Biochem. Biophys. Methods, 59: 145-157. DOI: 10.1016/j.jbbm.2003.12.005

Notomi, T., H. Okayama, H. Masubuchi, T. Yonekawa and K. Watanabe et al., 2000. Loop-mediated isothermal amplification of DNA. Nucleic Acids Res., 28: 1-63. DOI: 10.1093/nar/28.12.e63

Notomi, T., Y. Mori, N. Tomita and H. Kanda, 2015. Loop-mediated isothermal amplification (lamp): Principle, features and future prospects. J. Microbiol., 53: 1-5. DOI: 10.1007/s12275-015-4656-9

Nimitphak, T., W. Meemetta, N. Arunrut, S. Senapin and W. Kiatpathomchai, 2010. Rapid and sensitive detection of penaeus monodon nucleopolyhedrovirus (pemonpv) by loop-mediated isothermal amplification combined with a lateral-flow dipstick. Molecular Cell. Probes, 24: 1-5.

DOI: $10.1016 /$ j.mcp.2009.09.004

Prompamorn, P., P. Sithigorngul, S. Rukpratanporn, S. Longyant and P. Sridulyakul et al., 2011. The development of loop-mediated isothermal amplification combined with lateral flow dipstick for detection of vibrio parahaemolyticus. Lett. Applied Microbiol., 52: 344-51.

DOI: $10.1111 / \mathrm{j} .1472-765 X .2011 .03007 . \mathrm{x}$

Plaon, S., S. Longyant, P. Sithigorngul and P. Chaivisuthangkura, 2011. Rapid and sensitive detection of Vibrio vulnificus by loop-mediated isothermal amplification combined with lateral flow dipstick targeted to rpoS gene. Molecular Cell. Probes, 25: 158163.

DOI: $10.1016 /$ j.mcp.2011.04.001

Rauch, M.E., H.W. Graef, S.M. Rozenzhak, S.E. Jones and C.A. Bleckmann et al., 2006. Characterization of microbial contamination in united states air force aviation fuel tanks. J. Indus. Microbiol. Biotechnol., 33: 29-36.

DOI: $10.1007 / \mathrm{s} 10295-005-0023-\mathrm{x}$

Ryuji, K., D.B. Nedwell, K.J. Purdy and S.Q. Silva, 2004. Detection and enumeration of sulphatereducing bacteria in estuarine sediments by competitive PCR. Geomicrobiol. J., 21: 145-157.

Tomita, N., Y. Mori, H. Kanda and T. Notomi, 2008. Loop-mediated isothermal amplification (lamp) of gene sequences and simple visual detection of products. Nat. Protocols, 3: 877-882. DOI: $10.1038 /$ nprot.2008.57 